\title{
Erection of solid columns of one-storey industrial buildings with bridge cranes made of high-strength sandy concrete and its economic efficiency
}

\author{
Nikolay Palagin ${ }^{1 *[0000-0003-0059-5676]}$, Georgy Nikitin ${ }^{2}$, and Alexey Trunov ${ }^{3[0000-0002-6202-6084]}$ \\ ${ }^{1}$ Kazan State University of Architecture and Engineering, 420043, Kazan, Zelenaya st., Russia \\ ${ }^{2}$ Kazan Giproniiaviaprom OJSC, Kazan, Russia \\ ${ }^{3}$ KhIMPROMPROEKT LLC, Kazan, Russia
}

\begin{abstract}
The use of high-strength sandy concrete (HSSC) is an alternative to high-strength crushed stone. Its use is profitable for those regions of Russia in which crushed stone is an imported building material. Thus, crushed stone is supplied to the Republic of Tatarstan (RT) from the Ural, and the local reserves of sand are significant. Authors presented the results of studies to determine the economic efficiency of solid columns' erection in one-story industrial buildings with bridge cranes according to the 1.424.1-5 series from HSSC of HSSC60 and HSSC80 classes in comparison with heavy concrete of B20...B80 classes. Studies have shown that in relation to Kazan, the use of HSSC of HSSC60 and HSSC80 classes in comparison with heavy concrete of B20...B40 classes, depending on the size of the span, column spacing, floor height and lifting capacity of cranes, can reduce steel consumption by $43.2 \ldots 71.5 \%$. At the same time, the total cost of materials (steel and concrete) when using heavy concrete of B20...B40 classes is $1.7 \% \ldots 38.1 \%$ lower than with HSSC60 and HSSC 80. This is due to the sharp rise in the cost of concrete in the Russian market in the third quarter of 2002 and continuing to the present (second quarter of 2021). When recalculated before the indicated price increase, the use of HSSC60 and HSSC80 in comparison with heavy concrete of B20...B40 classes gives a decrease in the total cost of materials by $1.9 \ldots 34.5 \%$. The results obtained are novel because in the scientific and technical literature there is no information about the design of these columns from the HSSC.
\end{abstract}

Keywords: high strength sandy concrete, solid columns of one-storey industrial buildings with bridge cranes, economic efficiency.

\section{Introduction}

One of the promising areas in the field construction is associated with obtaining and economic efficiency of the use of high-strength crushed stone and sandy (fine-grained) concrete in reinforced concrete structures.

\footnotetext{
*Corresponding author: pal_nik11@mail.ru
} 
In [1], the authors investigated the durability of sandy concrete containing alcofine and zinc oxide and operated in unfavourable environmental conditions. The concrete mix has alcofine and zinc oxide of $10 \%$ and $2 \%$ by weight of the cement. River sand was replaced by technogenic partly or totally (in the amount of $25 \%, 50 \%, 75 \%$ and $100 \%$ ). Tests involving the action of acids, seawater, sulfates and chlorides on concrete showed the considerable durability of the mixture, in which the proportion of technogenic sand was 50 $\%$.

In [2], researchers proposed a mathematical model to describe the redistribution of chlorides in marine sandy concrete subject to atmospheric carbonization, which considered changes in porosity, saturation, and release of bound chlorides. Numerical simulations were performed using the COMSOL software on a random number theory model and validated against experimental data. The researchers can use the resulting model to predict the service life of marine sand concrete structures exposed to the atmospheric environment.

The aim of research [3] was the development of new sandy concrete with aggregate only from river sand (up to $4 \mathrm{~mm}$ ) or only dune sand $(0.63 \mathrm{~mm})$ and recycled plastic aggregates $(3.15 \mathrm{~mm})$. Authors studied various compositions by replacing sand with plastic aggregates at $0 \%, 25 \%, 50 \%$ and $75 \%$. Studies have shown that although the compressive strength of this replacement is reduced insignificantly, the thermal insulation and acoustic properties of concrete are significantly improved. When the sand was replaced up to $75 \%$, the sound absorption and the noise reduction coefficients varied from 0.15 to 0.6 for concrete with river sand and from 0.28 to 0.39 for concrete with dune sand. The resulting material is lightweight concrete, which according to ISO 11654 can be classified into sound absorption classes D and E. It can be used as a new building material.

Due to the high corrosion resistance of CFRP, its use with marine sandy concrete in coastal and offshore structures construction is promising. In this regard, in [4] and [5], the stress-strain state under axial compression of 40 cylindrical samples made of sea sand concrete, enclosed in a cage made of carbon fibre reinforced plastic, was investigated. The variable parameters were the types of the cage (solid and strip with different stripe pitch) and the number of CFRP layers. The authors analyzed fracture schemes, the relationship between axial and transverse deformations, and the distribution of ring deformations of the cage. The researchers compared test results with both existing stress-strain models and the proposed model. It turned out that the model proposed by the authors is the most accurate and universal.

Work [6] is a continuation of the previous studies of the authors. It was carried out on sandy concrete, with reduced density by introducing barley straw treated with hot water. This type of lightweight concrete had good thermophysical properties but had a relatively high shrinkage and low compressive strength. To improve the mechanical properties, researchers introduced steel fibres into the cement matrix. Authors investigated various percentages of steel fibre: $0 \% ; 0.5 \% ; 1 \% ; 1.5 \%$, and $2 \%$ - the most optimal of which in terms of thermophysical and mechanical properties turned out to be $1 \%$. These data were confirmed by microstructural analysis, which also showed good adhesion between the fibres used and the cement matrix. Compressive strength increased by $18 \%$, and shrinkage decreased by $30 \%$.

In [7], the authors studied using marble waste in the form of powder from a quarry in the northeast of Algeria by adding it in the form of sand to the composition of sandy concrete. The effect of replacing ordinary sand with marble in the amount of $25 \%, 50 \%$, $75 \%$ and $100 \%$ on the properties of concrete in a freshly prepared mixture (density, workability and air content) and the hardened state (compressive strength, tensile strength, surface hardness and sound velocity). The strength test was performed after placing the samples in water containing chlorides. Some limestone was added to reduce voids, and a superplasticizer was added to improve workability. The results showed that this 
replacement changed the characteristics of both fresh and hardened concrete compared to the control samples at a $0 \%$ degree of substitution while improving the strength indicators.

In [8], a seismic effect was studied in the form of an alternating cyclic load on square columns of steel pipes filled with aeolian sand concrete. 4 sample columns were tested. At the same time, their fracture form, hysteresis behaviour, and plasticity were analyzed. Experimental results have shown that such a casing design can optimize its mechanical properties and effectively improve seismic performance. The proposed theoretical model of the stress-strain state is in good agreement with the experimental results.

In [9], the results of experimental studies of the effect on workability, mechanical properties and durability of sandy concrete are given by using crushed granulated blastfurnace slag in its composition when replacing cement by $20 \%, 30 \%, 40 \%$ and $50 \%$. It was found that when replaced by $20 \%$, sandy concrete had the highest compressive and tensile strength, modulus of elasticity and abrasion resistance. The lowest chloride penetration corresponded to the replacement by $30 \%$.

In [10], the researchers studied the replacement in the composition of sandy concrete, consisting of $18 \%$ of cement, $37 \%$ of crushed sand, $33 \%$ of dune sand, and $12 \%$ of fly ash, of a part of cement by blast-furnace slag in the amount of $0 \%, 20 \%, 30 \%, 40 \%$ and $50 \%$. As a result of research, it was found that a $30 \%$ replacement is the most optimal.

In [11], the compositions of sandy high-strength concrete and the technology of manufacturing products from it are considered in conjunction with the assessment of their reliability and durability.

In [12], the results of studies are given to determine the economic efficiency of the construction of prefabricated and monolithic long cylindrical shells from HSSC of B60 and B80 classes in comparison with heavy concrete of B20-B80 classes. Studies have shown that, in relation to Kazan, the use of HSSC, compared with the heavy one, makes it possible to reduce the consumption of steel (up to $30.6 \%$ in prefabricated shells and up to $23.7 \%$ in monolithic ones), concrete (up to $15.9 \%$ in prefabricated shells and up to $14.0 \%$ in monolithic) and the total cost of materials (up to $18.9 \%$ in prefabricated casings and up to $20.3 \%$ in monolithic ones).

In [13], the researchers carried out experimental studies to optimize the composition of sandy concrete using DSC desert sand. Variable factors were water/cement ratio W / C, amount of fill sand and superplasticizer, and dune sand to fill sand D / F ratio. During the tests, the authors determined the slump of the concrete mixture, the air content, and the compressive strength at the age of 7 and 28 days. They proposed criteria for optimizing DSC mixture compositions for various construction requirements.

In [14], the authors carried out experimental studies on 66 standard cubes and 66 standard prisms of sandy concrete with different percentages of replacement of fill sand with dune sand (from $0 \%$ to $100 \%$ ). The cubic and prismatic compressive strength, tensile splitting strength and modulus of elasticity were determined. It was found that with an increase in the percentage of replacement of fill sand by dune sand, the compressive strength and splitting strength first decreases, then increases and finally decreases again, while the modulus of elasticity, the ability to dissipate energy and plasticity first increase and then decrease. The defining equation «stress-strain» is obtained.

In [15], the researchers studied the criterion for the sandy concrete destruction from the sand of coral reefs under biaxial compression. Experiments on cubes showed the dependence of strength on the ratio of the values of both stresses $\alpha$. At $\alpha=0.5$, the compressive strength turned out to be maximum. The deformation in the third direction becomes greatest at $\alpha \approx 0.25$. The envelope strength curve was obtained for all test results.

In [16], the authors studied the shrinkage deformations of sandy high-strength concrete for different loading ages $(7,28$, and 100 days). Based on the data of experimental studies, a theoretical description of shrinkage deformations is given. 
In [17], experimental studies of sandy concrete on man-made sand (MSC) and river sand (RSC) were carried out for multiple repeated loading in bending at constant maximum stress amplitude for five different characteristics of the cycle $\rho$. It was found that the flexural strength $\mathrm{R}_{\mathrm{r}}$ of MSC and RSC concretes corresponds to the two-parameter Weibull distribution, and the $\mathrm{R}_{\mathrm{r}}$ distribution for MSC concrete has less variability compared to RSC concrete. With the same $\rho$ value, MSC concrete shows a higher endurance limit $R_{r}$ than RSC concrete, for MSC concrete the $\mathrm{R}_{\mathrm{r}}$ value is less sensitive to changes in the $\rho$ value than for RSC concrete. The practical endurance limit $\mathrm{R}_{\mathrm{r}}$ (at $2 \times 10^{6}$ cycles) for MSC concrete is $55 \%$, which is $2 \%$ higher than for RSC concrete.

The article [18] presents the results of tests to determine the adhesion strength of polymer composite rods SFCB with marine sandy concrete when they are pulled out, and the bending characteristics of beams made of the same concrete, reinforced with SFCB rods after cooling the samples under load for 30,60 and 90 days alternately in dry environment and immersion in seawater. For comparison purposes, steel rod-reinforced control specimens were tested after being under the same conditions. It was revealed that in this case the maximum adhesion of the SFCB rods to concrete increases and the average adhesion value slightly decreases. The bond strength in specimens with steel reinforcement increased. When testing beams with steel bars, the magnitude of the characteristic loads did not change significantly, while when testing beams with SFCB bars, they decreased. The crack opening width in steel bar beams increased significantly, and this increase was not evident for SFCB beams. Residual deflections in all beams have increased.

It should be noted that there is a significant potential for the use of sandy concrete in additive technologies for the construction of buildings and structures using the $3 \mathrm{D}$ printing method. Numerous studies indicate the need for effective use of fine-grained concrete mixes in $3 \mathrm{D}$ printing technology due to the absence of a coarse aggregate, which leads to significant deformations of freshly printed layers and defects in its structure [19], [20].

The analysis of the works showed that only in one of them ([12]) authors investigated the question of the economic feasibility of designing building structures from high-strength sandy concrete.

Sandy concrete has many significant advantages over conventional heavy concrete, namely, high compressive and tensile strength, high-quality construction and high manufacturability, the ability to obtain thin-walled structures, decorative concrete and fibrereinforced concrete, etc. [21].

Sandy concretes also have disadvantages due to the large surface of the filled ones. It leads to increased cement consumption by $15-20 \%$ compared with equally strong heavy concrete. Therefore, in the manufacture of sandy concrete together with plasticizing ones, it is necessary to add mineral additives to the composition or use composite cement or cement of low water demand.

Also, sandy concrete has increased air entrainment. The manufacturers should use effective thinners or defoamers to reduce it.

In the Russian Federation, sand concrete is used due to the widespread availability of a raw material base. We know more than 50 sand deposits on the territory of the Republic of Tatarstan. The predicted resources of building sand in the republic are 1 billion $\mathrm{m}^{3}$, including real for processing - about 300 million $\mathrm{m}^{3}$. According to the safety strategy of the Republic of Tatarstan and the development of the natural resource complex of the Republic of Tatarstan for 2017-2021 and the prospect until 2030, the building materials industry is tasked with expanding the range of products manufactured from local mineral raw materials.

Since most of the European territory of Russia (Moscow, the Moscow region, the Volga region, Vologda, etc.) does not have deposits of coarse aggregate or deposits of sedimentary rocks, which are limited suitable for use in reinforced concrete, the use of 
sandy concrete is actual tested during its production. In addition, the extraction of stone and its processing into crushed stone requires significant energy consumption and is laborious. In addition, in the production of crushed stone, a fraction of more than $5 \mathrm{~mm}$ forms a large amount (up to 20-30\%) of screenings of a fraction of less than $5 \mathrm{~mm}$, occupying the same size and thereby violating the ecological balance of nature. Only a small amount of these wastes are used as raw materials for the preparation of limestone flour and mineral powder for asphalt concrete. The destruction of mountains during the extraction of crushed stone leads to irreversible climatic changes in Karelia, the North Caucasus and the Urals, which is not spread by the media. The use of sand as aggregate for concrete instead of the crushed stone causes less damage to the environment.

World construction practice is increasingly using high-strength and ultra-high-strength heavy concrete of a new generation, which can significantly reduce the size of the sections of elements, save concrete and reinforcement [22]. Their use has opened up almost endless possibilities for the unique buildings and structures construction around the world. In Russia, the introduction of such concretes began much later than in Western European countries, the USA, Canada and Japan. Some of the most famous objects built of heavy concrete classes B80...B90 are the buildings of the Moscow International Business Center (Moscow City) and the Lakhta-Center, public and business complex in St. Petersburg [23].

An alternative to high-strength heavy concrete is high-strength sandy concrete (HSSC) [16]. This formulation includes fractionated quartz sand, a highly active binder and effective modifiers. Reducing the amount of binder in concrete is achieved by grinding part of the sand, using plasticizing additives, and autoclaving the products. As additives, plasticizers are mainly used to reduce the water demand of the concrete mixture and the consumption of cement (C-3/2.5, Sika VC5-800/2.5, Metflux 2651/2.5) [21].

The use of HSSC has the following advantages: increased corrosion protection, reinforcement and resistance to chemically active substances, a decrease in the size of sections of structures or an increase in their bearing capacity.

The use of high-strength sandy concretes with the use of river sands of the Republic of Tatarstan and chemical additives is an alternative to traditional concretes. For the use of which high-strength crushed stone imported from the Urals is required.

On the basis of the sands of local deposits of the Kama, Volga and Vyatka rivers, compositions of high-grade sandy concrete HSSC60-HSSC80 have been developed at the Department of Technology of building materials, products and structures (TBMPS) of Kazan State University of Architecture and Engineering (KSUAE) [24]. The project «Highstrength sandy concrete» was included in the list of innovations in the field of building materials and technologies of the Ministry of Construction and Architecture of Housing and Communal Services of the Republic of Tatarstan. In 2017, at the instructions of the President of the Republic of Tatarstan, together with the State Housing Fund, the Department of TBMPS of KSUAE continued work on high-strength sand concrete. In particular, the scientists of this department, together with the specialists of $\mathrm{JCH}$ «Kazan GiproNiiAviaprom», completed an alternative design of the supporting frame of an 18storey residential building in the «Salavat Kupere» residential complex in Kazan from highstrength sandy concrete of B80 class instead of the initial project of heavy concrete of B25 class. As a result, savings in concrete amounted to $20 \%$, for steel reinforcement $-29 \%$ [24].

The article [25] presents the results of studies to determine the economic efficiency of erection of prefabricated and monolithic shallow shells of positive Gaussian curvature from HSSC of B60 and B80 classes in comparison with heavy concrete of B25-B80 classes. Studies have shown that, concerning Kazan, the use of HSSC, compared with the heavy one, makes it possible to reduce the consumption of steel (up to $36.0 \%$ in prefabricated casings and up to $43.0 \%$ in monolithic casings), concrete (up to $11.3 \%$ in prefabricated 
casings and up to $12.9 \%$ in monolithic ones) and the total cost of materials (up to $27.0 \%$ in prefabricated casings and up to $29.4 \%$ in monolithic casings).

Despite the listed advantages, today in the Republic of Tatarstan and Russia, the problem of the widespread use of HSSC is in the insufficiently rapid development of methods for calculating load-bearing structures made of it. In this regard, the use of sandy concrete is limited to coatings for roads, airfields and floors of industrial buildings, as well as the manufacture of small pieces and various decorative architectural and finishing products.

Following the above, it is necessary to continue the work on the design of various building structures from the HSSC. The only criterion for the effectiveness of its use should be economic feasibility. In this regard, the topic considered in the article is relevant for the construction industry development both in the Republic of Tatarstan and in Russia as a whole.

The purpose of the research was to identify the economic effect of erecting solid columns of one-storey industrial buildings with bridge cranes according to the series 1.424.1-5 «Reinforced concrete columns of the rectangular cross-section for one-storey industrial buildings with a height of $8.8 \ldots 14.4 \mathrm{~m}$, equipped with overhead travelling cranes with a lifting capacity up to 32 tons» from HSSC of HSSC60 and HSSC80 classes in comparison with heavy concrete of B20...B80 classes concerning Kazan.

\section{Materials and methods}

The authors considered two-span industrial building with a span of $\mathrm{L}=24 \mathrm{~m}$, a length of 72 $\mathrm{m}$ (equal to the size of the temperature block) with a column pitch of $\mathrm{B}=12 \mathrm{~m}$. A truss FB24III of the series 1.463.1-3/87 was used as a rafter structure, ribbed coating slabs $12 \times 3$ $\mathrm{m}$ - according to the 1.465.1-15 series with a reduced thickness of $89.7 \mathrm{~mm}$, single-layer expanded clay concrete wall panels - according to the 1.432-3 series, crane beams according to the 1.426.1-4 series. Each span contains 2 bridge cranes with A3 operating mode by GOST 34017-2016 (Fig. 1).

Two extreme options for the height of the building $\left(\mathrm{H}_{0}=14.4 \mathrm{~m}\right.$ and $\left.\mathrm{H}_{0}=8.4 \mathrm{~m}\right)$ and the lifting capacity of the cranes $(\mathrm{Q}=32 / 5 \mathrm{t}$ and $\mathrm{Q}=10 \mathrm{t})$ with technical and geometric characteristics by GOST 25711-83 were considered. A preliminary heat engineering calculation of the roof and wall was made. The collection of loads was carried out by SP 20.13330 «Loads and Impacts». Terrain type is B. Building class is KS-2.

Determination of forces (bending moments M, longitudinal $\mathrm{N}$ and transverse forces Q) in 4 design sections of columns (at the top of the columns, just above the top of the crane console, just below the top of the crane console, at the level of the foundation cutoff) can be performed in two ways: according to the engineering method of the joint venture 355.1325800 «Frame structures of reinforced concrete prefabricated one-storey buildings for industrial purposes. Design rules» and with the help of the LIRASAPR software package (PC). To select the calculation method, the efforts were determined in the extreme and middle columns of the building with a height of $\mathrm{H}_{0}=14.4 \mathrm{~m}$ and a lifting capacity of cranes $\mathrm{Q}=32 / 5 \mathrm{t}$ from loading with all 15 possible types of full design loads (from the dead weight of structures, snow, wind, crane vertical and horizontal). At the same time, to determine the efforts according to the engineering method, a calculation program was compiled in Microsoft Excel, the testing of which showed complete convergence with the results of manual counting.

Comparison of the efforts obtained by the engineering method and with the help of the SP«LIRA-SAPR», in all cases, showed the convergence of the values of the longitudinal forces. The convergence of the values of bending moments was observed in loadings with 
wind load and horizontal crane load. In other cases, there were significant or minor discrepancies.

Researchers chose the engineering method as the primary method. They also determined the efforts from the full standard loads and the long-term part of the full design and standard loads. In total, efforts were determined from all 27 possible types of full (calculated and standard) loads and their long-term parts. There is no analogue in domestic literature.

When compiling design combinations of forces in design sections of columns, according to SP 355.1325800, the following combinations were considered: 1) $M_{\max } N$; 2) $M_{\min } N$; 3) $N_{\max } M_{\max }\left(M_{\min }\right)$; 4) $N_{\min } M_{\max }\left(M_{\min }\right)$. Load selection rules and combination coefficients $\psi_{l i}, \psi_{t i} \Lambda \psi_{\text {cr. }}$. were accepted according to SP 20.13330 .

Researchers performed the following calculations of the columns for the calculated combinations of forces: 1) calculation according to the group I of limiting states: longitudinal reinforcement of the column trunk in the plane of the transverse frame (according to the formulas of symmetric and asymmetric reinforcement, regardless of the ratio of the values of multidirectional bending moments) and from its plane; transverse reinforcement of the column shaft in the plane of the transverse frame; longitudinal and transverse reinforcement of the column console; 2) calculation for the II group of limiting states: for the formation and opening of normal cracks.

Following SP 63.13330 «Concrete and reinforced concrete structures. Basic provisions» and the methodological manual «Calculation of reinforced concrete structures without prestressed reinforcement» (to SP 63.13330.2012) researchers drew up flowcharts and corresponding calculation programs in Microsoft Excel. According to them authors performed calculations for the above options for the space-planning solution of buildings and lifting capacity of cranes for the classes of ordinary heavy concrete B20, B30, B40, B60 and B80 and HSSC of the classes HSSC60 and HSSC80 (56 cases in total).

The class of longitudinal reinforcement was accepted as A500C, transverse and structural - A240C and B500C, angular and sheet products - from steel C245. The strength and deformation characteristics of reinforcement and heavy concrete were taken according to SP 63.13330, and high-strength sandy concrete - according to the data of the Department of TBMPS of KSUAE. It should be noted that for the same class of concrete, the strength characteristics of HSSC $\left(\mathrm{R}_{b}, \mathrm{R}_{\mathrm{bt}}, \mathrm{R}_{\mathrm{b} \text {,ser }}, \mathrm{R}_{\mathrm{bts}, \mathrm{ser}}\right)$ exceed their values for heavy concrete by $\mathrm{a}$ factor of $1.05 \ldots 2.05$, and the modulus of elasticity $\mathrm{E}_{\mathrm{b}}$ is $1.02 \ldots 1.04$ times less.

For all considered classes and types of concrete and calculation cases, researchers determined the consumption of materials (concrete and reinforcement) in the end columns of the K4 formwork and the middle columns of K9 [26] and their total cost. At the same time, the composition of heavy concrete and HSSC were adopted according to the development of the Department of TBMPS of KSUAE, the cost of heavy concrete, HSSC, reinforcement and rolled steel, according to the design organization LLC «VOLGANEFTEGAZPROEKT» (Kazan) as of the first quarter of 2021.

It should be noted that in the Russian market in the third quarter of 2020 the cost of concrete, reinforcement and rolled steel increased sharply. For the types and classes of concrete considered in the studies, the cost increased by 1.5 ...2.5 times (the higher the class of concrete, the higher the price rise), the classes and diameters of reinforcement - by 1.3...1.7 times, rolled steel - by 1.2...1.3 times. This growth continues to date (second quarter of 2021). 


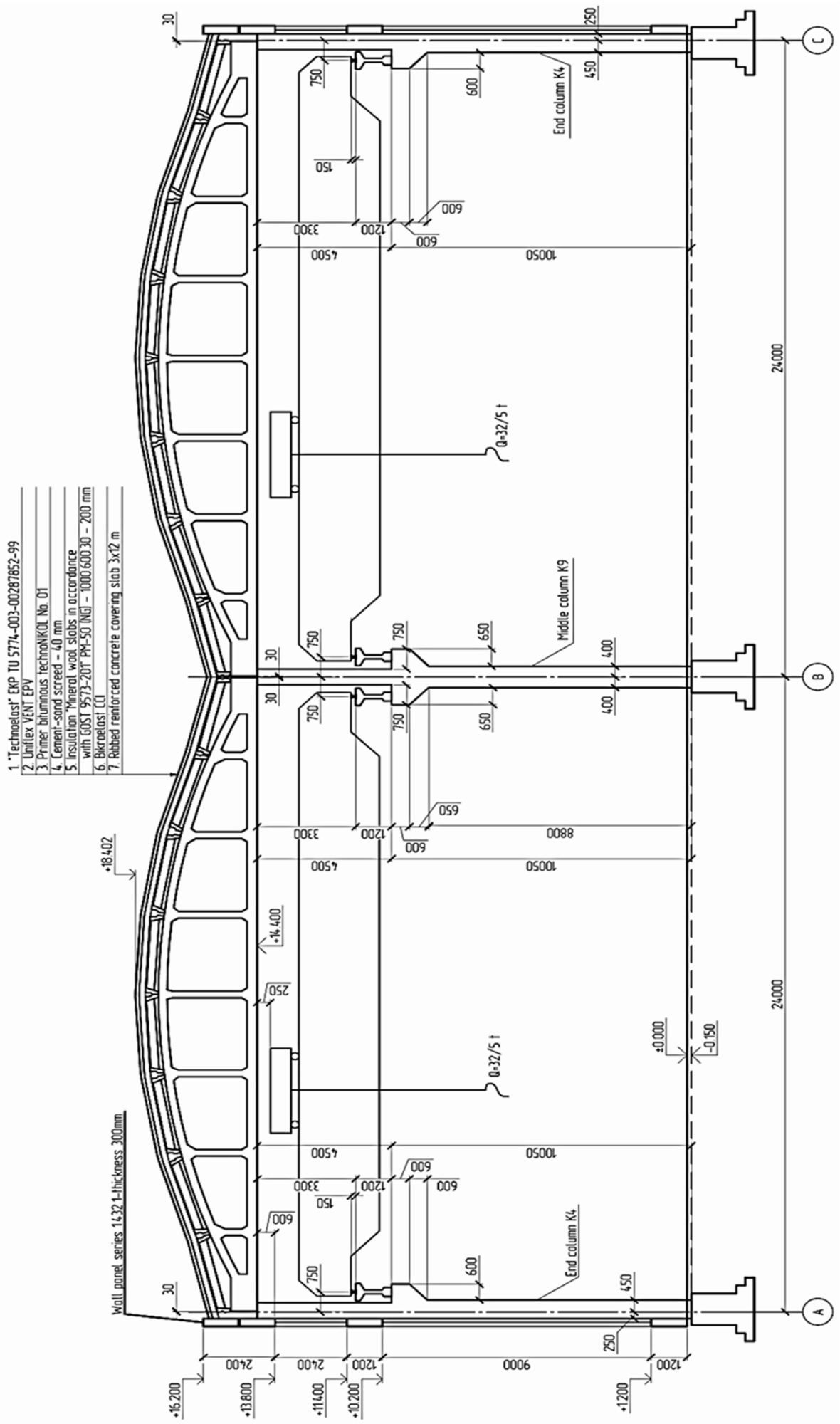

Fig. 1. Cross section of a one-storey industrial building with bridge cranes. 


\section{Results}

As a result of calculations, the authors revealed that with a difference in the magnitudes of multidirectional bending moments in the absolute value of more than $25 \%$, the calculation by the method of asymmetric reinforcement gives a $10 . .50 \%$ smaller area of reinforcement than by the method of symmetric reinforcement. With a moment difference of no more than $25 \%$, calculations by both methods give close values of the square. Basically, this is confirmed in the available literature. But it does not indicate the proximity of the values of the areas obtained in the calculation according to the methods of symmetric and asymmetric reinforcement for the second case. It simply states that the calculation should be performed according to the method of symmetric reinforcement.

In all the cases considered, the strength of the column shaft along the inclined section was ensured only by the strength of the concrete, and the requirements for crack resistance were always met with the number of reinforcement set based on the calculation for group I of limit states. At the same time, to ensure the strength of normal sections from the plane of the transverse frame, it was sometimes necessary to increase the amount of longitudinal reinforcement determined by calculation in the plane of the frame. The strength of the cantilevers along the inclined sections in all cases was provided by concrete alone.

The graphs of the dependences of the steel consumption and the cost of materials in extreme $\mathrm{K} 4$ and middle K9 columns for the cases considered the authors showed in Fig. $2 . . .5$.

Comparison of the technical and economic indicators of the extreme and middle columns made of heavy concrete of classes B20...B80 and HSSC60 and HSSC80 for eight considered cases of space-planning solution and lifting capacity of overhead cranes showed the following:

- in terms of the total cost of materials (reinforcement, rolled steel and concrete), the most economical in 4 cases was the use of heavy concrete of class B30, in two cases - heavy concrete of class B20, in one case - heavy concrete of class B40 and high-strength sandy concrete of class HSSC80. In these cases, when using heavy concrete of classes B20...B40, savings compared to high-strength sandy concrete of HSSC60 and HSSC 80 classes ranged from $1.7 \%$ to $38.1 \%$, compared with heavy concrete of classes B60 and B 80 - from $2.4 \%$ to $38.2 \%$;

- the total cost of materials for the manufacture of columns from heavy concrete of B60 and B80 classes and high-strength sandy concrete of HSSC60 and HSSC80 classes is practically the same;

- an increase in the class of heavy concrete from B60 to B80 does not reduce the total cost of materials, except one case $\left(\mathrm{K} 9, \mathrm{H}_{0}=14.4 \mathrm{~m}, \mathrm{Q}=32 / 5 \mathrm{t}\right)$, when the savings amounted to $8 \%$;

- an increase in the class of high-strength sandy concrete from HSSC60 to HSSC80 does not reduce the total cost of materials, except for two cases $\left(\mathrm{K} 9, \mathrm{H}_{0}=14.4 \mathrm{~m}, \mathrm{Q}=32 / 5 \mathrm{t}\right.$ and $\mathrm{K} 9, \mathrm{H}_{0}=14.4 \mathrm{~m}, \mathrm{Q}=10 \mathrm{t}$ ) when the savings were $7.8 \%$ and $2.9 \%$, respectively;

- the use of high-strength sandy concrete of classes HSSC60 and HSSC80 in comparison with heavy concrete of B20...B40 classes reduces steel consumption by $43.2 \ldots 71.5 \%$;

- with an increase in the class of heavy concrete from B20 to B60, steel consumption, as a rule, decreases. For heavy concrete B60 and B80 classes, steel consumption is usually the same;

- steel consumption in the manufacture of columns from heavy concrete of classes B60 and B80 and high-strength sandy concrete of HSSC60 and HSSC80 classes is practically the same. 


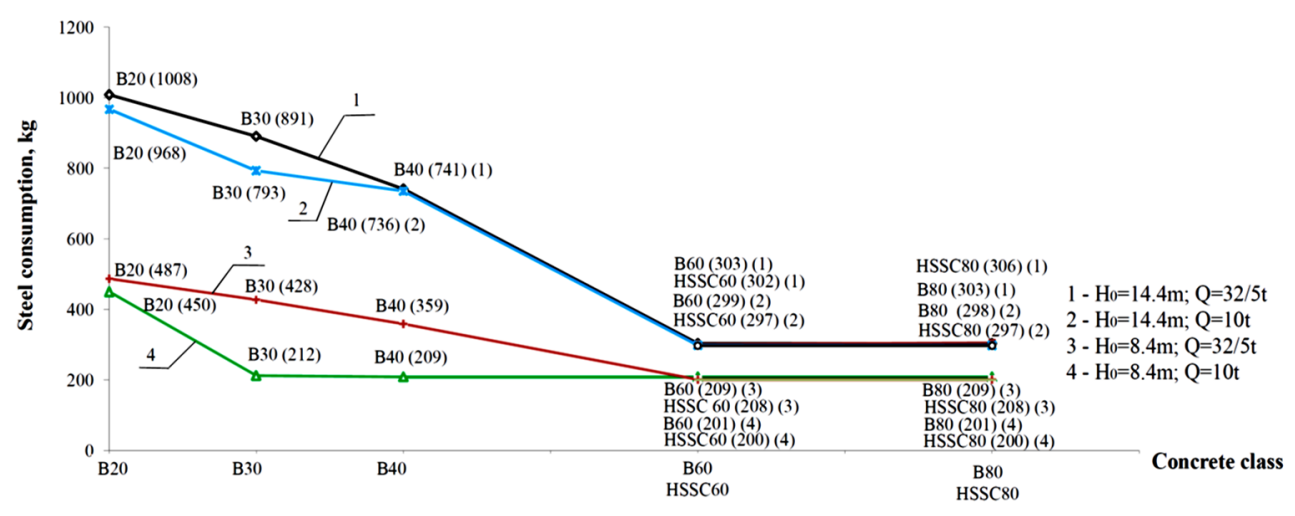

Fig. 2.Dependency graphs of the steel consumption in the extreme column K4 on the type and class of concrete at $\mathrm{L}=24 \mathrm{~m}, \mathrm{~B}=12 \mathrm{~m}, \mathrm{~kg}$.

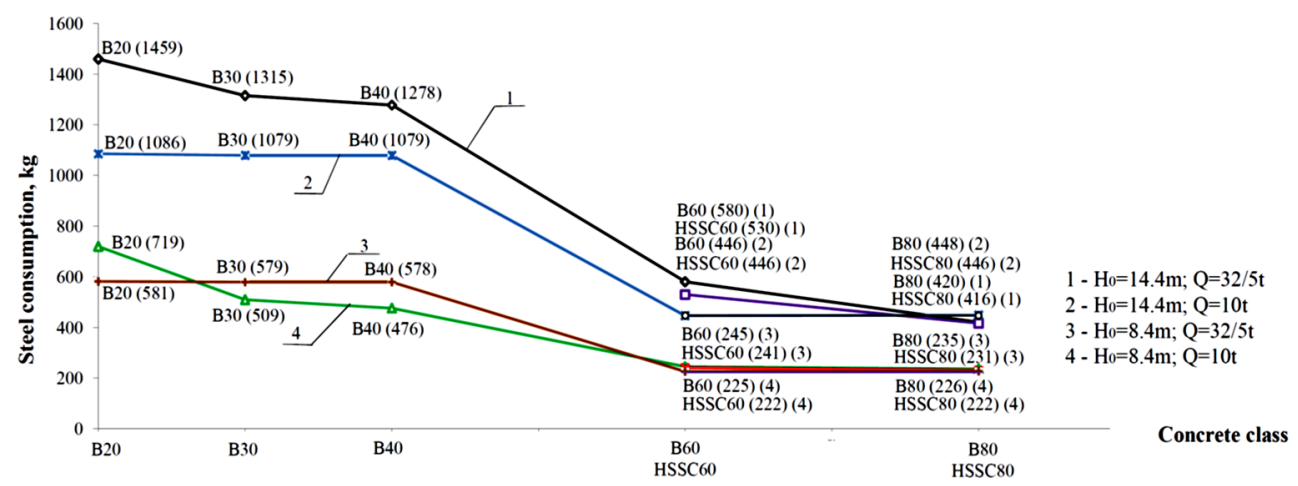

Fig. 3. Dependency graphs of the steel consumption in the middle column K9 on the type and class of concrete at $\mathrm{L}=24 \mathrm{~m}, \mathrm{~B}=12 \mathrm{~m}, \mathrm{~kg}$.

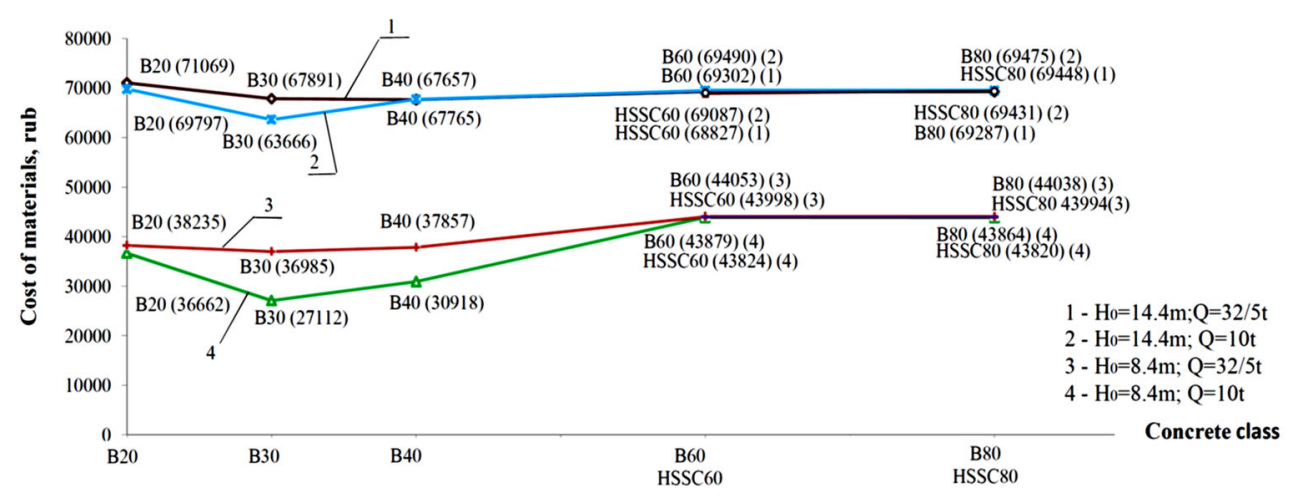

Fig. 4. Dependency graphs of the cost of materials of the extreme column K4 on the type and class of concrete at $\mathrm{L}=24 \mathrm{~m}, \mathrm{~B}=12 \mathrm{~m}$, rub. 


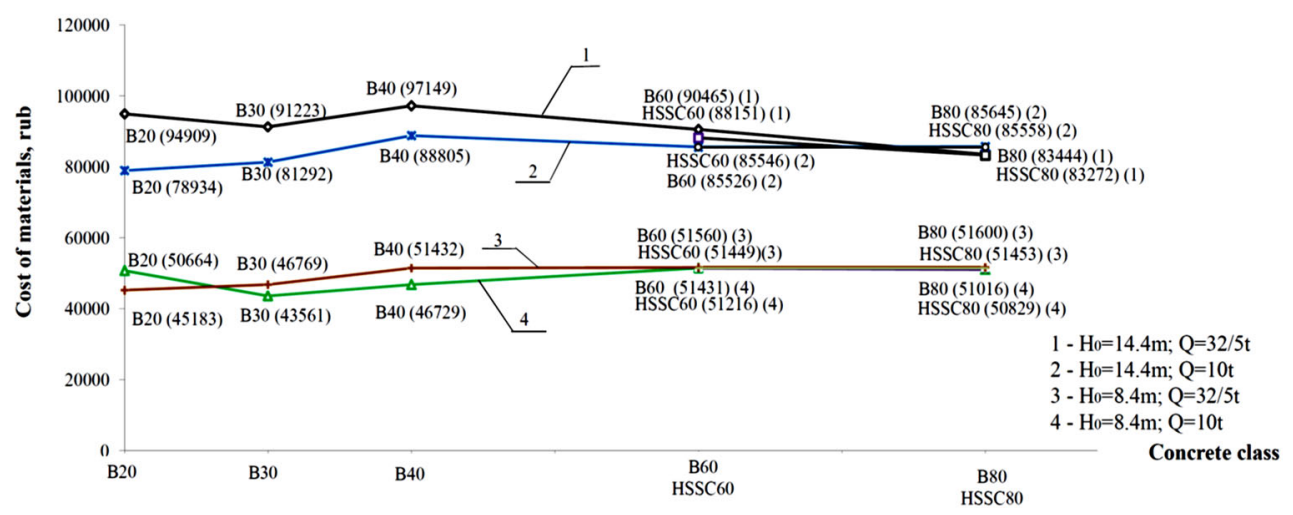

Fig. 5. Dependency graphs of the total cost of materials of the middle column K9 on the type and class of concrete at $\mathrm{L}=24 \mathrm{~m}, \mathrm{~B}=12 \mathrm{~m}$, rub.

\section{Discussion}

In the scientific and technical literature, it was possible to find only information about the economic efficiency of designing long cylindrical shells, shallow shells of positive Gaussian curvature and an 18-storey residential building and solid columns of one-storey industrial buildings with overhead cranes (see the Introduction).

In this regard, it can be concluded that the obtained results are novel, and the results of the carried out studies can be recommended for use in construction practice.

\section{Conclusions}

The use of high-strength sandy concrete (HSSC) is an alternative to high-strength crushed stone. In the scientific and technical literature, there is no information about the design of solid columns of one-storey industrial buildings with bridge cranes.

The performed studies have shown that concerning Kazan, the use of HSSC of classes HSSC60 and HSSC80 compared to heavy classes B20...B40 allows to reduce, depending on the size of the span, the pitch of the columns, the height of the floor and the lifting capacity of the cranes, the consumption of steel by $43.2 \ldots 71.5 \%$.At the same time, the total cost of materials (steel and concrete) was $1.7 \ldots 38.1 \%$ higher.

It should be noted, that the indicated increase in the total cost of materials is associated with a sharp rise in the cost of concrete in the Russian market, which occurred in the third quarter of 2020, and continuing to the present (II quarter of 2021). When recalculating the total cost before the indicated price increase, the use of high-strength sandy concrete of the HSSC60 and HSSC80 classes in comparison with the heavy concrete of the B20...B40 classes gives a decrease in the total cost of materials by $1.9 \ldots 34.5 \%$. The results obtained are novel because in the scientific and technical literature there is no information about the design of these columns from the HSSC. In connection with the obtained economic effect, the results of the research can be recommended for use in construction practice.

\section{References}

1. K. Thangapandi, R. Anuradha, P. Awoyera, R. Gobinath, N. Archana, M. Berlin, O. Oladimeji, Silicon, 13(4), 1079-1085 (2021) DOI:10.1007/s12633-020-00494-2 
2. W. Liu, L. Tang, F. Xing, Constr. Build. Mater., 274, 121962 (2021) DOI: 10.1016/j.conbuildmat.2021.121962

3. A. Boucedra, M. Bederina, Y. Ghernouti, Constr. Build. Mater., 256, 119447 (2020) DOI: $10.1016 /$ j.conbuildmat.2020.119447

4. J. Yang, J. Wang, Z. Wang, Compos. Struct., 246, 112373 (2020) DOI: 10.1016/j.compstruct.2020.112373

5. J. Yang, J. Wang, Z. Wang, Compos. Struct., 246, 112368 (2020) DOI: 10.1016/j.compstruct.2020.112368

6. M. Ammari, B. Belhadj, M. Bederina, A. Ferhat, M. Quéneudec, Constr. Build. Mater.,233, 117374 (2020) DOI: 10.1016/j.conbuildmat.2020.117374

7. B. Ouassila, H. Houria, K. Leila, B. Mouloud, A. Assia, R. Chaher, Adv. Concr. Constr., 9(2), 217-225 (2020)

8. Y. H. Wang, Y. P. Wang, G. Huo, M. Zhao, J. Qi, H. Wang, P. Liu, Journal of Engineering and Applied Science, 67(8), 2093-2108 (2020)

9. N. Sang, N. Khoa, Lect. Notes Civ. Eng., 54, 409-414 (2020)

10. T. Nguyen, L. Chu, Lect. Notes Civ. Eng., 54, 403-408 (2020)

11. A. Tolstoy, E. Fomina, A. Milkina, IOP Conf. Ser. Mater. Sci. Eng., 753(3), 032036 (2020)DOI: $10.1088 / 1757-899 X / 753 / 3 / 032036$

12. N. Palagin, A. Dul'miyeva,IOP Conf. Ser. Mater. Sci. Eng., 890, 012078 (2020) DOI: 10.1088/1757-899X/890/1/012078

13. W. Yan, G. Wu, Z. Dong, Constr. Build. Mater., 226, 469-482 (2019)

14. Z. Li, G. Wang, S. Yang, G. Ju, YingyongLixueXuebao, Chinese Journal of Applied Mechanics,36(5), 1131-1137 (2019)

15.Z. Peng, D. Li, Y. Zhou, S. Ren, Wuhan LigongDaxueXuebao, Journal of Wuhan University of Technology, 40(5), 66-70 (2018)

16. N. Karpenko, S. Kaprielov, I. Bezgodov, G. Moiseenko, M. Stepanov, Izv. Vyss. Uchebnykh Zaved. Seriya Teknol. Tekst. Promyshlennosti, 3, 227-230 (2018)

17. B. Li, L. Yin, L. Fan, Jianzhu Cailiao Xuebao, Journal Build. Mater., 20(5), 801-807 (2017)

18. Z. Dong, G. Wu, Y. Xu, J. Compos. Constr. 21(2), 04016095 (2017)

19. R. Mukhametrakhimov, L. Lukmanova, Mag. Civ. Eng., 102(2), 10206 (2021)

20. R. Mukhametrakhimov, L. Lukmanova, in IOP Conf. Ser. Mater. Sci. Eng., 890, 1 (2020)

21. N. Morozov, V. Khozin, H. Muginov, Building Materials Journal, 9, $72-73$ (2010)

22. S. Mindess, Developments in the formulation and reinforcement of concrete, 1-423 (2019)

23. E. Ilyukhina, S. Lakhman, A. Miller, V. Travush, Construction sciences, 3, 110-121 (2019)

24. Il-T. Mirsayapov, G. Nikitin, V. Simakov, Izv. KGASU, 3 (45), 145-152 (2018)

25. N. Palagin, G. Nikitin, A. Sadrutdinova, Erection of gentle shells of positive Gaussian curvature from high-strength sandy concrete and its economic efficiency/Construction and development: life cycle, in Materials of the V Int. (XI All-Russia) Conf., 25-26 November, 2020,Cheboksary, Russia (2020)

26. N. Palagin, Design of reinforced concrete columns of solid rectangular section: Study guide (Kazan state university of architecture and engineering, Kazan, 2017) 